\title{
O ENCONTRO DE SABERES NAS UNIVERSIDADES. UMA SÍNTESE DOS DEZ PRIMEIROS
}

\author{
ANOS \\ JOSÉ JORGE DE CARVALHO \\ LETÍCIA C. R. VIANNA
}

\begin{abstract}
RESUMO
Este artigo sintetiza a experiência do Encontro de Saberes, movimento iniciado em 2010 na Universidade de Brasília pelo INCT de Inclusão no Ensino Superior e na Pesquisa (INCTI/UnB/CNPQ) e cuja expansão já alcançou 14 universidades públicas no território nacional, uma na Colômbia e uma na Áustria. 0 Projeto é a realização concreta e efetiva de uma proposta descolonizadora do pensamento e da prática acadêmica no âmbito do ensino superior e da pesquisa. 0 foco deste movimento é a inclusão dos mestres e mestras dos saberes dos povos tradicionais, indígenas, afro-brasileiros, quilombolas e das culturas populares como docentes nas universidades em disciplinas regulares. Apresentamos os indicadores gerais de sua expansão, uma conceituação aprofundada do sentido dos termos mestre e mestra e do papel do professor parceiro como anfitrião.
\end{abstract}

\section{PALAVRAS-CHAVE \\ Encontro de Saberes; Pluralidade epistêmica; Descolonização.}

\section{THE MEETING OF KNOWLEDGES IN THE UNIVERSITIES. A SUMMARY OF THE FIRST TEN YEARS}

\begin{abstract}
This article summarizes the experience of the Meeting of Knowledge in Brazilian Universities, a movement initiated in 2010 at the University of Brasilia by the INCT for Inclusion in Higher Education and Research (INCTI / UnB / CNPQ) and whose expansion has already reached 14 public universities in Brazil, one in Colombia and one in Austria. The project is the concrete and effective realization of a decolonizing proposal for academic thought and practice in the field of higher education and research. The focus of this movement is the inclusion of people with acknowledged higher knowledge (mestre and mestra) from indigenous, Afro-Brazilian people, maroons and traditional popular cultures as teachers in universities in regular courses. We present the general indicators of its expansion and an in-depth conceptualization of both the meaning of the terms mestre e mestra, and of the role of their partner lecturer.
\end{abstract}

\section{KEYWORDS}

Meeting of Knowledge; Epistemic plurality; Decolonization.

\section{RENCONTRE DE SAVOIRS DANS LES UNIVERSITÉS. UN RÉSUMÉ DES DIX PREMIÈRES ANNÉES}

\section{RÉSUMÉ}

Cet article résume la expérience de la Rencontre de Savoirs dans les universités brésiliennes - qui a été lancée en 2010 à l'Université de Brasília par l'Institut national des sciences et technologies pour l'inclusion dans l'enseignement supérieur et la recherche (INCTI / UnB / CNPQ) ; et dont l'expansion a déjà atteint 14 
universités publiques en Brésil, une université en Colombie et une université en Autriche. Le projet est la réalisation concrète et efficace d'une proposition décolonisante pour la pensée et la pratique académiques dans le domaine de l'enseignement supérieur et de la recherche. L'objectif de ce mouvement est l'inclusion d'hommes e de femmes sages ayant une connaissance approfondie des communautés traditionnels, autochtones, afro-brésiliens, groupes urbains de cultures populaires en tant qu'enseignants dans les universités dan marrons, les matières ordinaires. Nous présentons les indicateurs généraux de son expansion et une conceptualisation en profondeur de la signification des termes mestre e mestra, qui sont la raison d'être du mouvement.

\section{MOTS CLÉS \\ Rencontre de Savoirs; Pluralité épistémique; décolonisation. \\ ENCUENTRO DE SABERES EN LAS UNIVERSIDADES. RESUMEN DE LOS DIEZ PRIMEROS AÑOS}

\section{RESUMEN}

Este artículo resume la experiencia del Encuentro de Saberes en las Universidades Brasileñas, movimiento iniciado en 2010 en la Universidad de Brasilia por el Instituto Nacional de Ciencia y Tecnología para la Inclusión en la Educación Superior e Investigación (INCTI / UnB / CNPQ), y cuya expansión ya alcanzó a 14 universidades públicas en el territorio nacional, una universidad en Colombia y una en Austria. El Proyecto es la realización concreta y efectiva de una propuesta descolonizadora para el pensamiento y la práctica académica en el campo de la educación superior y la investigación. El objetivo de este movimiento es incluir a los sabedores (mestres y mestras) de pueblos tradicionales, indígenas, afrobrasileños, cimarrones (quilombolas), de culturas populares urbanas, como docentes en las universidades en materias regulares. Presentamos los indicadores generales de su expansión y una conceptualización en profundidad del significado de los términos mestree mestra, que son la razón de ser del movimiento.

\section{Palabras Clave}

Encuentro del saber; pluralidad epistémica, descolonización. 


\section{UMA SÍNTESE DO ENCONTRO DE SABERES}

Ao longo de todo o século XX, as universidades brasileiras se mantiveram estruturadas sob o paradigma eurocêntrico e monoepistêmico de conhecimento, articulado com a exclusão de classe, raça e etnia entre professores e estudantes. Esse padrão somente foi alterado no início do século XXI, quando foram implementadas as políticas de cotas raciais destinadas a confrontar a segregação étnica e racial crônica e comum a todas elas. Menos de uma década após a entrada de estudantes cotistas negros, indígenas e das classes populares em todos os cursos, desencadeamos um processo complementar, que denominamos de inclusão epistêmica, através do movimento do Encontro de Saberes.

O Encontro de Saberes é um projeto de inovação epistêmica e pedagógica iniciada em 2010 pelo Instituto Nacional de Ciência e Tecnologia de Inclusão no Ensino Superior e na Pesquisa (INCTI), sob a coordenação de José Jorge de Carvalho, e com intenso trabalho executivo e reflexivo de uma rede composta por mestres e mestras, professores, professoras e estudantes das mais variadas áreas do saber acadêmico. Trata-se da inclusão de mestres e mestras oriundos de sociedades indígenas, comunidades de terreiro, quilombolas, agroextrativistas, grupos urbanos de diferentes culturas e demais povos tradicionais para atuarem como docentes nas universidades. Essa intervenção no sistema acadêmico cresce articulada com outras que também impulsionam processos de inclusão epistêmica, como as ações derivadas das leis 10.639 e 11.645 no âmbito das licenciaturas. Mais especificamente, o Encontro de Saberes é uma resposta à demanda colocada pelos mestres e mestras nos dois Seminários Nacionais de Políticas Públicas para as Culturas Populares, realizados em 2005 e 2006 pelo Ministério da Cultura Após décadas de expropriação, canibalização e espetacularização, os mestres adquiriram consciência do seu valor e compreenderam que deveriam projetar sua voz nas escolas sem intermediários². Assim, os Seminários permitiram um novo pacto educativo das comunidades tradicionais com o Estado. Nesse contexto, a pauta de demandas dos mestres se revelou mais forte do que em qualquer momento histórico anterior a este e a potência do termo "mestre" reflete esse novo pacto.

O projeto tem suscitado uma agenda de prolífica produção teórica, metodológica, pedagógica e política por parte da nossa rede de docentes, mestres, mestras e estudantes; e ao mesmo tempo, um esforço análogo de articulação e rearranjo institucional por parte dos

\footnotetext{
${ }^{1}$ Ver Seminário Nacional de Políticas Públicas para as Culturas Populares (2005) e II Seminário Nacional de Políticas Públicas para as Culturas Populares (2006).

${ }^{2}$ Sobre expropriação, canibalização e espetacularização, ver Carvalho (2004; 2010a).
} 
gestores das universidades que aderiram ao movimento. A fundamentação teórica e a sistematização dos dados vêm se acumulando em uma série de publicações, abrindo várias áreas de diálogo interepistêmico ${ }^{3}$. Partindo dessa produção, que organizamos no final como uma Bibliografia básica de consulta, apresentamos aqui o aprofundamento de dois aspectos tocados em trabalhos anteriores, porém atualizados especificamente como contribuição ao primeiro dossiê sobre o Encontro de Saberes preparado por uma revista acadêmica de Antropologia. São eles: a) uma síntese dos indicadores extraídos de todas as edições da disciplina Encontro de Saberes realizadas até agora4; b) uma conceituação e uma reflexão mais detalhada do significado dos termos "mestre" e "mestra" que estão no centro do movimento, e que simplesmente não existiria sem eles.

A partir da experiência inicial na Universidade de Brasília em 2010, o movimento foi crescendo a ponto de que hoje já totalizam 16 universidades com disciplinas oferecidas: além da UnB, a Universidade Federal Minas Gerais (UFMG), Universidade Federal de Juiz de Fora (UFJF), Universidade Federal do Vale do Vale do Jequitinhonha e Mucuri (UFVJM), Universidade Federal do Sul da Bahia (UFSB), Universidade Federal do Pará (UFPA), Universidade Federal do Cariri (UFCA), Universidade Estadual do Ceará (UECE), Universidade Federal do Rio Grande do Sul (UFRGS), Universidade Federal Fluminense (UFF), Universidade do Rio de Janeiro (UFRJ), Universidade Federal de Roraima (UFRR), Universidade da Integração Internacional da Lusofonia Afro-Brasileira (UNILAB); Universidade da Música de Viena e a Pontifícia Universidade Javeriana de Bogotá.

Até agora foram envolvidos 161 mestres e mestras de diversos territórios de saberes, 127 professores e professoras de diferentes áreas do conhecimento acadêmico, aproximadamente 3.093 estudantes, e realizadas cerca de 4.065 horas aula ${ }^{5}$. Dessas 15 universidades, duas implementaram pela primeira vez disciplinas em 2020. Observa-se uma tendência consolidada de expansão para outras universidades que começam a se articular com a

\footnotetext{
${ }^{3}$ Para uma fundamentação básica do projeto, em sequência cronológica, apresentamos uma seleção dos artigos principais: Carvalho (2010b; 2011; 2012; 2015; 2016; 2017; 2018; 2019a; 2019b; 2020a; 2020b; 2020c; 2020d), Carvalho e Flórez (2014a; 2014b), Carvalho e Águas (2015), Carvalho, Flórez e Ramos (2017), Carvalho, Kidoiale, Costa e Carvalho (2020), Carvalho e Costa (2020), Carvalho et al (2016a; 2016b; 2016c) e Figueiredo e Vianna (2020).

4 Para a construção dos indicadores e desta síntese dos dez anos do projeto, contamos com a colaboração e a generosidade dos colegas da Rede do Encontro de Saberes, a quem manifestamos nossa intensa gratidão.

${ }^{5}$ Para o mapeamento dos mestres e mestras do Encontro de Saberes, ver Carvalho, Vianna e Salgado $(2015 ; 2016)$.
} 
Rede, e a construir bases para a implementação do Projeto, como é o caso da Universidade Federal do Rio Grande do Norte-UFRN, e Universidade Federal do Rio Grande - FURG, que desenvolvem projetos de extensão como uma primeira aproximação da proposta com a estrutura da universidade com vistas ao futuro aprimoramento da experiência em cursos de graduação; e também outras universidades como a Universidade Federal da Paraíba (UFPB), Universidade Federal de Uberlândia (UFU) e a Universidade Estadual de Santa Catarina (UDESC), que já aprovaram disciplinas para o presente ano.

\section{Figura 1. Quadro Geral do Encontro de Saberes 2010-2020.}

\section{Quadro Geral do Encontro de Saberes 2010-2020}

Disciplinas Implementadas

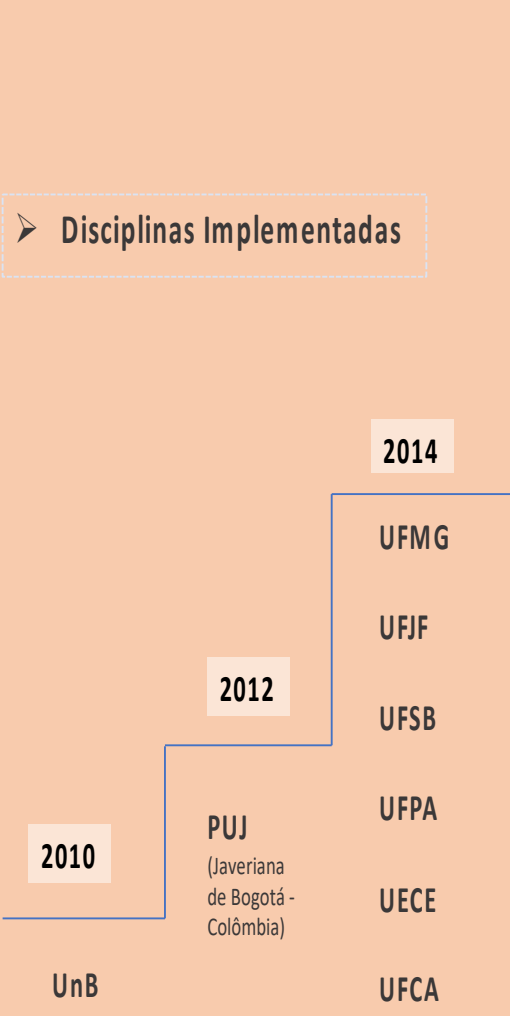

Experiências Parciais: UFES; FURG; UFRN

Projetos Aprovados: UFPB; UFU; UDESC, UFT

Projetos em Discussão: UFPel; UFPE; UEMG; UFBA

Fonte: INCTI/UnB/CNPq

Em todos esses casos, trata-se de uma intervenção no mundo acadêmico em várias dimensões: de inclusão étnico-racial, política, pedagógica, institucional/administrativa e epistêmica. As duas primeiras dimensões são mais evidentes, pois ao trazer mestres e mestras dos povos tradicionais e dos grupos urbanos de tradições culturais diversas para dentro da universidade enquanto pesquisadores e docentes, estamos rompendo com uma prática secular 
de exclusão étnico-racial nas universidades no país. Para além da proposição descolonizadora no plano das ideias, a operacionalização da proposta é, em si, a campanha política que se trava no âmbito institucional para uma refundação do modelo de universidade que herdamos do século XX brasileiro.

É fato que, por um lado, as universidades, por demanda de seus institutos e departamentos, podem reconhecer a relevância do saber dos mestres. Entretanto, a estrutura administrativa nem sempre conta com meios e instrumentos jurídicos para a contratação dos mestres como docentes, uma vez eles que não detêm nem a escolaridade nem a titulação necessária para atender às regras correntes. Esta é a razão por que muitas vezes a estratégia inicial para a abertura de um caminho institucional se dá por via da Extensão, para com o tempo abrir disciplinas na graduação e/ou pós-graduação. A realização do projeto só se torna plenamente viável com um rearranjo dos procedimentos institucionais para que pessoas não diplomadas também possam lecionar no lugar dos professores doutores. O caminho seguido até agora acumula soluções temporárias, táticas ou mesmo estratégicas até que o aparato legal/administrativo permita garantir a presença dos mestres e mestras, com a mesma capacidade que já garante a presença dos professores substitutos ou visitantes.

Em cada universidade onde aconteceram edições da disciplina, as experiências foram realizadas em diferentes formatos e arranjos, abrangendo várias áreas de conhecimento, na extensão, graduação e pós-graduação. Em algumas já foram consolidados meios de institucionalização e continuidade, como é o caso da UFMG, UFSB, UFRGS, UFF e UnB, que criaram condições básicas da gestão no âmbito das Pró-Reitorias e da administração central, e continuam desenvolvendo experiências e mecanismos que proporcionem a realização da disciplina.

Um dos meios mais eficazes e efetivos de reconhecimento e contratação daqueles que não são portadores de diploma de mestrado e doutorado é a outorga do título de Notório Saber, quando um Conselho Universitário admite que o saber dos mestres tradicionais seja equivalente ao de um doutor acadêmico. ${ }^{6}$ Além de ministrarem disciplinas, cada vez mais vemos mestres e mestras atuando em grupos de pesquisa, participando de bancas, palestras, seminários e co-orientações. A proposta do projeto mantém afinidades com as perspectivas transdisciplinares, o que não é corrente nas grades curriculares e nos procedimentos dos diversos cursos das nossas universidades marcadamente eurocêntricas e de formato humboldtiano. A construção de cada encontro, em cada disciplina e atividade acadêmica,

\footnotetext{
${ }^{6}$ Sobre o Notório Saber, ver Carvalho $(2016 ; 2020$ c).
} 
demanda um esforço do professor em romper com as suas fronteiras disciplinares de modo a construir uma interlocução produtiva com o mestre como seu parceiro de curso e com os estudantes. Os mestres e mestras que participam do projeto são, em sua maioria, polímatos detêm conhecimentos em diferentes áreas do saber - e atuam junto com professores parceiros que dominam conhecimentos acadêmicos especializados em áreas com fronteiras disciplinares bem demarcadas. Assim, cada edição do Encontro de Saberes coloca para os professores parceiros o desafio de construir a interface dos saberes tradicionais com algumas áreas dos conhecimentos acadêmicos. E o desafio posto à academia é superar o nível disciplinar e alcançar - ou ao menos vislumbrar - a perspectiva inter/transdisciplinar e polímata do mestre, que mesmo na condição de professor substituto ou visitante - portanto, temporário - coloca-se como referência para um rearranjo epistêmico do funcionamento do nosso ensino superior.

Um exemplo de polímato é o mestre Maniwa Kamayurá, que participou das primeiras edições do projeto na Universidade de Brasília, e que transita por diversas áreas do saber de um modo contínuo e integrado. Em primeiro lugar, ele é um notório conhecedor do modo de construção das casas tradicionais xinguanas. Contudo, ele não é apenas um arquiteto pois, além de projetar, constrói a casa sendo, portanto, também um engenheiro. Quando ensinou na UnB, o seu professor parceiro foi da área de Arquitetura, mas poderia ter sido um professor da área de Engenharia. O mestre narra mitos que vinculam as casas xinguanas à cosmologia dos povos do Xingu - e, assim, seu módulo poderia ser desenvolvido com um professor parceiro da Literatura. Ele também desenha, tendo um inquestionável vínculo com as nossas Artes Visuais. Além disso, Maniwa é um reconhecido pajé, conhecedor de plantas e práticas de promoção da saúde e cura, o que o colocaria como docente da Faculdade de Saúde e ou do Departamento de Botânica. Sua polimatia se baseia na capacidade de dialogar com diferentes áreas do estilo fragmentado do conhecimento científico cultivado nas universidades; e desafia-nos concretamente ao exercício da reintegração ou religação dos saberes em uma perspectiva transdisciplinar.

Como Maniwa, outros mestres e mestras de diversas comunidades, detentores de diferentes saberes, preparam cuidadosamente a proposta de cada disciplina em um diálogo com o professor parceiro. De fato, cabe aos professores parceiros se empenharem na preparação das ementas, programas, instrumentos pedagógicos e formas de regência de classe conjuntamente com mestras e mestres. Assim, não se pretende, por enquanto, a construção de um protocolo geral interepistêmico рага o Encontro de Saberes, mas o desenvolvimento de protocolos particulares, específicos para os diálogos nas diversas áreas do saber, em cada experiência em particular. 
Os métodos de transmissão de conhecimento utilizados pelos povos tradicionais são muito variados e quase sempre baseados na oralidade, na escuta e na prática contínua e cotidiana. Pensando no modelo junguiano das quatro funções de captação do conhecimento, podemos dizer que os seus processos de ensino integram razão, emoção, intuição e sensação, e acionam consistentemente instâncias do sagrado e do profano; e alcançam e formam o indivíduo na sua integralidade como sujeito ativo do conhecimento. ${ }^{7}$ Por outro lado, no nosso ambiente acadêmico, a vida cotidiana de quem ensina e de quem aprende é suspensa e são afastadas, com exceção da área das Artes, as instâncias da intuição, da sensação e da emoção. Guiadas quase exclusivamente pela função pensamento, a leitura, a escrita e a escuta do professor são os instrumentos pedagógicos por excelência, em um tipo de ensino que privilegia a aula expositiva ${ }^{8}$.

As universidades que aderiram à proposta do Encontro de Saberes experimentaram, na dimensão pedagógica, desafios de inovação no ensino que combinaram métodos e instrumentos consagrados na academia com métodos e instrumentos usuais nas comunidades tradicionais de cada mestre e mestra. Assim, cada experimento, cada encontro de aprendizes/ alunos com um certo mestre ou mestra e um certo professor ou professora, em um módulo de aula sobre um determinado tema, é um evento exclusivo em forma e conteúdo, com modos próprios de interação e, pelo menos por enquanto, resultados únicos de aprendizagem.

Apresentamos a seguir alguns indicadores que sintetizam a intensidade e a amplidão da revolução epistêmica promovida pelo Encontro de Saberes nos últimos dez anos. De 2010 a 2020 já participaram 161 mestres de diferentes universos culturais: indígenas, quilombolas, comunidades de terreiro, e de grupos organizados nas cidades e zonas rurais em torno de performances e celebrações das culturas populares tradicionais; e também 127 professores de diferentes áreas do conhecimento estabelecidas pelo CNPq que acompanharam os mestres em sala de aula.

\section{Comunidades de Pertencimento dos 161 Mestres e Mestras}

Indígenas - 21 etnias: Ashaninka, Pancararú, Guarani Mbyá, Huni Kuin, Kanindé, Ka'apor, Guarani Kaiowá, Kamayurá, Krenak, Krahô, Matipú, Maxacali, Pataxó, Pitaguary, Tremembé, Tukano, Kubeo, Xavante, Yanomami, Yawalapiti, Ye'kuana - 54 mestres (34\%)

\footnotetext{
${ }^{7}$ Sobre os tipos psicológicos, ver Jung (2003).

${ }^{8}$ Sobre a aula expositiva dos acadêmicos e a aula de transmissão dos mestres, ver Carvalho e Costa (2020).
} 
Comunidades de Terreiro: Candomblés Ketu, Jeje, Nagô, Angola; Umbandas (RJ, MG, DF, BA, PE, CE, RR) - 21 mestres (13\%)

Quilombolas - 11 Comunidades: Saco Curtume (PI) Custaneira (PI), Itacaré (BA), São José (RJ), Namastê (MG), Carrapatos de Tabatinga (MG), Luízes (MG), Mato do Tição (MG), Cedro (GO), Kalunga (GO), Alpes (RS) - 13 mestres (8\%)

Comunidades de agricultores, extrativistas e pescadores: BA, MG, RJ, AM - 24 mestres $(14,9 \%)$

Agrupamentos rurais e urbanos em torno de tradições populares: Reisado, Folias, Bumbas, Cavalo Marinho, Congado, Cantorias, Repente, Cordel, Cordão de Pássaros, Jongo, Samba, Carimbó, Capoeira - 49 mestres $(30,4 \%)$

\section{Comunidades de Pertencimento Acadêmico dos 127 Professores e Professoras - Pela CLASSIFICAÇÃO DO CNPQ}

Ciências Exatas - Matemática, Física, Biologia, Botânica - 10 professores (7,8\%)

Engenharia - Engenharia aeroespacial -1 professor (0,8\%)

Ciências da Saúde - Educação Física, Enfermagem, Nutrição - 6 professores (4,7\%)

Ciências Agrárias - Agronomia, Veterinária, Zootecnia, Ciências ambientais - 4 professores $(3,1 \%)$

Ciências Sociais Aplicadas - Arquitetura, Ciência da Informação, Museologia, Comunicação - 10 $(7,8 \%)$

Ciências Humanas - Antropologia, Educação, Estudos Culturais, Etnomusicologia, Filosofia, Geografia, História, Psicologia, Sociologia - 79 (62,2\%)

Linguística, Letras e Artes - 17 professores $(13,4 \%)$

Dessa síntese, ressaltamos algumas correlações significativas na linha da inclusão epistêmica. Primeiro, observamos que os indígenas estão super-representados no total de mestres e mestras: eles são apenas 0,4\% da população brasileira, porém são 34\% do total de docentes no Encontro de Saberes. Essa presença marcante pode ser compreendida quando lembramos que a maior diversidade epistêmica com que contamos no Brasil vem dos 305 povos indígenas, que falam pelo menos 180 línguas distintas. Sem nenhum planejamento de nossa parte, na medida em que o projeto foi se ampliando, colegas professores foram convidando mestres e mestras indígenas que conheciam. Essa presença contundente, surgida naturalmente, nos dá uma ideia da dimensão da diversidade epistêmica represada e também do consequente 
empobrecimento epistêmico com que convivemos desde o início do Século $X X$, quando as nossas primeiras universidades foram fundadas.

O mesmo raciocínio vale para interpretar a super-representação dos povos de terreiro e dos quilombos: cada um representando apenas 04\% da população total, os povos de terreiro contam, respectivamente, com $13 \%$ e os quilombolas com $8 \%$ do total de mestres e mestras. Ou seja, 08\% em escala demográfica contribuem com $21 \%$ da diversidade epistêmica total incluída pelo Encontro de Saberes. E se juntarmos agora povos de terreiro, quilombolas, comunidades de agricultores e extrativistas e agrupações de culturas populares, sendo todos eles compostos quase exclusivamente de pessoas negras, eles representam mais de $60 \%$ do total de mestres e mestras. Como os indígenas são 34\% dos mestres e mestras, podemos concluir que a inclusão epistêmica promovida pelo Encontro de Saberes é também, inegavelmente, uma inclusão étnica e racial na docência, em uma dimensão sem precedentes e insubstituível.

Quanto ao quadro dos professores parceiros, ele espelha bem a diversidade de áreas de conhecimento dos mestres e mestras. E o fato de existir uma concentração nas áreas de Humanidades e Artes entre os docentes pode ser compreendido porque a luta descolonizadora é liderada por docentes dessas áreas. Assim, tanto na super-representação epistêmica de negros e indígenas quanto na predominância das áreas expressivas e argumentativas entre os professores, fomos vendo aflorar o inconsciente político descolonizador da nossa academia logo que um processo de ruptura com o eurocentrismo foi posto em marcha.

Estes indicadores revelam, com nitidez, que já contamos com um modelo concreto e operacional para efetuarmos a passagem de uma universidade brasileira eurocêntrica, monolíngue, monocultural e monoepistêmica para uma universidade multicultural, poliglota e pluriepistêmica, preparada para incorporar as tradições epistêmicas com que contamos: as ocidentais, orientais, indígenas e as afro-brasileiras. O Encontro de Saberes constrói, assim, um microcosmo da transformação que almejamos nas universidades em larga escala; isto é, não de algumas disciplinas isoladamente, mas de todos os cursos, centros, faculdades e institutos.

As experiências das disciplinas, tanto em cursos de graduação como na pós-graduação, seguem princípios básicos, tais como: remuneração dos mestres compatível com a dos professores substitutos com doutorado; perspectivas inter e transdisciplinares; inseparabilidade entre teoria e prática; tratamento das dimensões sagradas e afetivas como meios legítimos de compreensão do mundo; estímulo à leitura, à escrita, à escuta e à performance.

O Encontro de Saberes inova tanto pelos temas trazidos com ineditismo ao universo acadêmico, quanto pelo contraste ou choque epistêmico e metodológico entre os processos 
pedagógicos correntes nas universidades e os modos de transmissão do conhecimento próprios dos mestres e mestras das tradições. O encontro dos saberes acadêmicos com os saberes tradicionais nos ambientes universitários implica, assim, na inovação curricular e na criação de disciplinas que se realizam segundo esse novo horizonte ancorado na incorporação plena da oralidade e no exercício da polimatia.

Esses dez anos de experiências proporcionaram uma sistematização ou visualização de áreas peculiares ao movimento. Estas áreas são classificações abstratas, construídas a posteriori das experiências. Contudo, podem funcionar como indicadores para efeito de sistematização da diversidade das realizações, proporcionando bases para a reflexão acerca da renovação epistêmica nos processos pedagógicos realizados:

1) Espiritualidade; 2) Saúde e Cura: 3) Meio Ambiente/Produção de Alimentos, 4) Artes das Performances/Celebrações, 5) Artesanato/Tecnologias; 6) Mediação e Liderança; 7) Cosmologia/Filosofia.

Na experiência do projeto nas 14 universidades brasileiras foram faladas as seguintes línguas, além do português:

Indígenas: Ashaninka, Mbyá, Huni Kuin, Ka'apor, Kaiowa, Kamayurá, Krenak, Krahô, Matipú, Maxacali, Pataxó, Tukano, Kubeo, Xavante, Yanomami, Yawalapiti , Ye'kuana.

Africanas: Iorubá, Kimbundo.

O Encontro de Saberes é um movimento que vai se ampliando e se complexificando, com implicações de curto, médio e longo prazo no ensino, na pesquisa e na gestão pública; e na medida em que se consolida, vai impactando a formação de professores, pesquisadores, gestores públicos e prestadores de serviço para o Estado e a sociedade. Leva a perspectiva da descolonização do plano meramente teórico e abstrato para a realização concreta e efetiva de uma academia pluriepistêmica, onde os conhecimentos tradicionais e científicos, orientados por perspectivas convergentes, divergentes, compatíveis, incompatíveis, comensuráveis e incomensuráveis possam conviver com equidade de espaço e legitimidade.

\section{SOBRE O CONCEITO DE MESTRE E MESTRA}

O foco central do Encontro de Saberes é a promoção dos saberes tradicionais nãoeurocêntricos nas universidades, os quais serão ensinados não mais exclusivamente por docentes e pesquisadores de formação eurocêntrica, mas também (e prioritariamente) pelos 
mestres e mestras das comunidades tradicionais que preservam, transmitem e recriam esses saberes, em um regime de diálogo, equanimidade e colaboração. Podemos justificar a atuação dos mestres como docentes universitários respondendo a três questões: a) os critérios utilizados para decidir quais mestres iremos convidar para ensinar nas universidades; b) as dimensões e as caraterísticas do saber dos mestres; e c) a legitimação e certificação do seu saber.

Com relação à primeira pergunta, os mestres e mestras que convidamos são escolhidos por serem pessoas de senioridade inequívoca segundo a avaliação dos membros das suas comunidades. Certamente, em inúmeros casos, pode existir mais de um mestre ou mestra reconhecidos em uma mesma comunidade tradicional, e tomamos a decisão de convidar um deles conscientes de que outros e outras também poderiam ocupar o mesmo papel. Essa escolha é influenciada em grande parte pela relação dos professores com os mestres e mestras através de suas pesquisas e seus trabalhos colaborativos com as comunidades. Além dos professores, influenciam nossas escolhas outras referências de pesquisadores, apoiadores, jornalistas, produtores culturais e gestores de organismos do Estado nas esferas municipal, estadual e federal que tenham efetuado algum tipo de reconhecimento aos mestres. Por exemplo, muitos mestres e mestras participaram em projetos de Extensão nas universidades, ocasião em que suas habilidades como docentes foram testadas e comprovadas. Neste sentido, o que devemos escolher no Encontro de Saberes são mestres de saberes tradicionais para ensinar - ou seja, escolhemos um tipo especial de docente, e aqueles que já desempenharam esse papel através da Extensão ou de outros projetos tornam-se naturalmente mais visíveis.

Quanto à segunda questão, referente às dimensões do saber dos mestres, é possível distinguir quatro principais, sendo as duas primeiras definidoras, ou suficientes, para justificar academicamente o lugar que ocuparão como docentes:

a) os mestres são aqueles que assumiram a missão de ensinar o que sabem e têm discípulos, aprendizes, assistentes, seguidores ou auxiliares. Entre eles estão os que foram plenamente formados pelo seu mestre e se colocam na condição de assumir futuramente o papel de novos mestres - ou mesmo em alguns casos já o são. O modelo pedagógico básico do Encontro de Saberes é que o mestre ou mestra venha dar aula acompanhado de seus discípulos mais formados - ao ponto de que já tivemos módulos ministrados por dois mestres exatamente da mesma tradição, o mais novo sendo por sua vez discípulo do mais velho.

b) os mestres são os grandes conhecedores das tradições que praticam e as expandem ao longo do tempo, assumindo, além da docência, a condição de pesquisadores. Essa condição dupla de serem, por um lado, transmissores do conhecimento estabelecido, e por outro, criadores de novas variantes ou de uma expansão desse patrimônio de conhecimento, é 
justamente o que garante a outorga que recebem, pelas suas comunidades e por nós, do título de mestres e mestras. A condição de um grau reconhecido de autonomia do saber é um distintivo dos mestres para que sejam convidados a atuar como nossos colegas temporários.

Uma característica marcante da dimensão de expansão dos saberes da maioria dos mestres, e que os coloca em uma condição análoga à nossa enquanto pesquisadores, é o trabalho que a maioria deles realiza de recuperar saberes de todas as áreas - técnicas antigas, cantos, danças, histórias, narrativas míticas, entre outras. Recuperar um saber disperso ou ameaçado de extinção é um modo de apresentar um conhecimento novo, porque refeito e reencarnado. Dito de outro modo, um sentido forte da pesquisa para os mestres é atualizar constantemente os patrimônios científicos, tecnológico, artístico, político e espiritual das suas comunidades 9 .

Enquanto a pesquisa dos acadêmicos estimula a especialização, a pesquisa dos mestres intensifica a polimatia. Sinteticamente, o mestre é aquele que se aperfeiçoa no saber tradicional, aproximando-se da figura do cientista, do tecnólogo, do artesão, do artista, enfim, do praticante de habilidades que são coletivas, porém que ele domina de um modo integral ou completo. Contudo, muito raramente nos deparamos com mestres tradicionais que sejam especializados em um único tipo de conhecimento. Se o cientista é o que sabe o que a maioria não sabe, o mestre é cientista no plural, isto é, o que sabe, sozinho, vários tipos e áreas do conhecimento que somente a soma de muitas pessoas sabe. A polimatia é uma forma de conhecer generalizada nas comunidades tradicionais, e alcança a condição de mestre aquele que a exerce com uma habilidade excepcional.

Na sala de aula, o mestre oferece o seu saber e simultaneamente apresenta a sua biografia que ancora esse saber. Ou seja, ao ensinar o que sabe, ele transmite também quem ele é. Deste modo, expõe uma falta constitutiva da condição moderna do acadêmico, que é a irrelevância e o descarte, como professor, da própria biografia. Como o argumenta Jacques Lacan, apoiado em dois grandes epistemólogos do século XX, a saber, Alexandre Koyré e Karl Popper, o sujeito da ciência moderna é o sujeito vazio cartesiano ${ }^{10}$. Esse esvaziamento subjetivo, que separou radicalmente a ciência moderna da ciência antiga, serviu de orientação, desde o Iluminismo, para o modo de funcionamento de todos os que ingressam na instituição acadêmica (docentes, discentes e técnicos administrativos). Inspirado na figura emblemática do mestre

\footnotetext{
9 Sobre o Encontro de Saberes e salvaguarda do patrimônio cultural ver Vianna (2020).

${ }^{10}$ Ver Lacan (1998).
} 
antigo, que foi Sócrates, George Steiner refletiu, em Lições dos Mestres (2018), sobre a ausência da figura do mestre na academia ocidental contemporânea. Onde havia mestres, temos agora especialistas, cada vez mais circunscritos a áreas, subáreas, disciplinas e subdisciplinas. Todos os exemplos de mestres antigos trazidos por Pierre Hadot, em sua vasta obra sobre a filosofia antiga, são de pessoas que construíram uma biografia rica, exercitando todas as suas faculdades - além da inteligência e o saber racional, os afetos, as emoções, intuições, habilidades manuais, participação na vida comunitária e religiosa ${ }^{11}$.

Esta concepção da filosofia (e, por extensão, da mestria) como uma maneira de viver se assemelha fortemente ao comportamento dos nossos mestres tradicionais, pois todos eles estão engajados plenamente no cotidiano das suas comunidades. O grande saber que acumularam e que vêm agora nos transmitir foi adquirido ao mesmo tempo em que adquiriam todos os demais saberes prescritos pelas suas comunidades segundo sua condição de gênero e segundo as demais funções que exercem (econômicas, sociais, religiosas, políticas, etc).

c) o termo mestre é utilizado também para designar aquele que lidera a tradição ou a agrupação cultural, como o coco, maracatu, folia, pastoril, etc. Além disso, os mestres são, efetivamente, grandes lideranças comunitárias, atuando, para além dos seus saberes específicos, como porta-vozes e autoridades encarnadas dos seus coletivos diante de instâncias tanto internas quanto externas às comunidades. Claro que nem todos os mestres necessitam exercer essa condição no nosso contexto acadêmico, porém a sua imagem de representante de seu grupo, comunidade ou agrupação transparece para nós, docentes parceiros, e também para os alunos.

Na maioria dos casos, a habilidade de liderar é herdada familiarmente, ainda que seja comum a intervenção espiritual para se alcançar essa realização. Essa dimensão da habilidade de liderança e do exercício da autoridade é a mais legitimada pela comunidade de origem do mestre e menos controlada, em sua avaliação, pelos acadêmicos que o convidam para a universidade. Ainda assim, o perfil de liderança impacta na sala de aula e condiciona a pedagogia dos mestres e mestras pois reforça, aos olhos dos alunos, o seu lugar da autoridade, praticamente indissociável do conteúdo do que vai ensinar.

d) finalmente, os mestres e mestras encarnam um quarto tipo de realização do conhecimento que é mais abstrato, sutil, menos mensurável e que se tornou extremamente raro no nosso mundo acadêmico: a condição de sábio ou de sábia. A encarnação biográfica do mestre tradicional como uma alternativa e complemento ao docente/pesquisador universitário conduz

${ }^{11}$ Ver Hadot $(2014 ; 2020)$.

Revista Mundaú, 2020, n. 9, p. 23-49 
a uma solução para a ausência da figura do sábio na academia, que podemos conceituar como aquele conhecedor e mestre capaz de se apresentar como alguém que integra aquilo que sabe com aquilo que é. Daí o impacto positivo e inspirador dos mestres nas aulas, tanto para os alunos como para os professores, ambos carentes do contato com um sabedor ou sabedora que encarne pessoalmente a maestria que demonstra possuir.

Acreditamos que o Encontro de Saberes conecta-se com a crise epistêmica profunda, presente em todo o mundo, do modelo acadêmico eurocêntrico moderno e expressa o espírito do nosso tempo, marcado pelas iniciativas, em todos os continentes, de retomada dos saberes tradicionais, ancestrais, originários, indígenas - encarnados, no caso das nossas universidades, nos seus mestres e mestras.

Os mestres do Encontro de Saberes trilham todos um mesmo movimento epistêmico percebido em três etapas que podem ser definidas como: aquele que sabe e que domina completamente uma área de conhecimento (seja um artesão, uma raizeira, um mestre de tradições performáticas, um artista de terreiro) passa do lugar de um conhecedor (o equivalente do que seria para nós um docente que faz pesquisa) ao lugar de um mestre (o conhecedor sênior que tem discípulos de seu conhecimento) ; e esse mestre pode converter-se em uma tela projetiva na qual identificamos a figura do sábio. Dito de outro modo, o conhecedor sênior que é mestre torna-se a imagem da sabedoria.

Um efeito dos dois Seminários de Políticas Públicas para as Culturas Populares que mencionamos no início foi generalizar o uso do termo mestre e mestra para denominar a todas as pessoas de referência dos saberes tradicionais, incluindo indígenas, quilombolas, das comunidades afro-brasileiras, das culturas populares e de todos os tipos de comunidades tradicionais. No contexto de mobilização pelo apoio aos mestres e mestras provocada pelos Seminários, o termo assumiu um estatuto tanto descritivo como analítico; isto é, tanto uma categoria emic para muitas tradições e comunidades, quanto etic para os vários sujeitos extracomunitários envolvidos nessa promoção: produtores culturais, mediadores, pesquisadores, acadêmicos, gestores do Estado, jornalistas. É possível avaliar que essa generalização do termo foi um ganho político, conceitual e institucional, na medida em que permitiu unificar as diversas frentes de demanda por políticas públicas sem retirar as especificidades de cada tipo de mestre e mestra. Assim, encontramos a denominação de mestres de capoeira, de reisado, de cavalo marinho, de folia de reis, de jurema, de formas de artesanato, de tecnólogos de vários tipos, entre outras. Por outro lado, outras tradições utilizam termos diferentes para designar suas lideranças: amo de boi, capitão de Congado, de Nau Catarineta; reis e rainhas de Reinado, de Quicumbi; pai de santo e mãe de santo para as religiões de matriz africana, pajés e xamãs para 
tradições indígenas de cura; raizeiras, benzedeiras, parteiras, рara sabedoras da área da cura e do cuidado.

Já na primeira edição do Encontro de Saberes trouxemos um mestre de arquitetura e engenharia indígena, Maniwa Kamaiurá; um mestre indígena de reflorestamento conectado com a agroecologia, Benki Pianko; e uma mestra da área da saúde, Lucely Pio, especialista em plantas medicinais. Logo outras mestrias que extravasam as expressões culturais em um sentido estrito começaram a aparecer, como mateiros, marisqueiros, agroecólogos, mestres de pesca artesanal, de construção de barcos, etc. Para o Encontro de Saberes, portanto, o conceito de mestre e mestra abarca os especialistas em toda a gama de saberes consolidados de todos os povos tradicionais (afro-brasileiros, indígenas e quilombolas) e de todas as agrupações das culturas populares tradicionais.

Esse conceito englobante que emergiu dos Seminários decantou-se nos anos seguintes através do seu uso no Encontro de Saberes até transformar-se em um conceito plenamente analítico, obviamente com base no seu uso local. Assim como outros conceitos que se generalizaram, como o de "indígena", de "candomblé", por exemplo, que acolhem uma grande diversidade de termos locais, convivemos com uma aceitação ou acomodação do conceito analítico de mestre por parte dos sabedores tradicionais que se auto-denominam de outro modo. Por exemplo, nenhum pai de santo ou mãe de santo deixará de se denominar com estes termos para passar a autoapresentar-se como mestre e mestra; ele ou ela aceitarão essa denominação genérica, conscientes das motivações por trás de uma política de valorização dos seus saberes no meio universitário. Não é diferente a utilização dos termos xamã ou pajé para designar uma imensa variedade de especialistas no mundo espiritual e da cura nos 305 povos indígenas brasileiros. Ressaltamos, assim, que a denominação de mestre não expropria os povos tradicionais de seus sistemas próprios de organização de produção e transmissão de saberes. Diante deste quadro complexo, o Encontro de Saberes absorve a unificação do termo e projetao no espaço até uma década atrás distante do universo de atuação dos mestres e mestras, que é a universidade. Ao trazê-los para a academia, tornamos um pouco mais consistente a polissemia do termo e a amplitude política e social de seu uso e do seu consequente impacto.

A condição de mestre se generaliza nacionalmente, abrangendo os sabedores tradicionais de todas as comunidades, povos, etnias e agrupações tradicionais do país. Paralelamente, vai se generalizando também como um sujeito de conhecimento que contribui para todas as instituições do Estado: universidades, escolas, institutos de Patrimônio, Embrapa, instituições de pesquisa em saúde, meio ambiente, meteorologia (como no caso do Ceará), pesca, entre outras. E esse reconhecimento nas comunidades, na academia e nas demais 
instituições do Estado reverbera também nas organizações da sociedade civil, como ONGs, Sistema S e empresas de produção cultural. Ou seja, se até há pouco tínhamos o significante professor ou docente como o único termo para designar o ensino e o conjunto do conhecimento dito científico, agora o termo mestre se apresenta como uma alternativa e complemento à figura do professor.

\section{O CONCEITO DE MESTRE EM UMA PERSPECTIVA COMPARADA}

O termo "mestre", tal como o usamos no Encontro de Saberes, e que pode ser reconhecido igualmente pelo Ministério da Educação e pelas instituições públicas estaduais e municipais é, neste momento, quase único entre as línguas cujos significantes próximos ou análogos conseguimos ter acesso através de tradução e de consultas a especialistas. Em praticamente todas elas é preciso de mais de um termo para traduzir o significado atual que damos a esta palavra em português. Na maioria das outras línguas com que temos familiaridade, dois termos são utilizados para o que chamamos de mestre: um para designar aquele(a) que ensina, e outro para designar aquel(a) que sabe, ou que pesquisa (cientista ou artista, resumidamente).

Se tomarmos as grandes tradições dos povos andinos, principalmente de língua quechua, é ressaltada a figura do amawta, o instrutor, professor ou mestre que ensina os conhecimentos ancestrais; e a figura do pesquisador, do cientista tradicional é definida pelo termo yachay. Em japonês o termo sensei também aglutina a função do professor e instrutor das artes marciais; e shihan acrescenta um honorífico à condição genérica de sensei, indicando um grande conhecedor. A mesma oposição passa para a língua chinesa, entre shifu (o professor, o instrutor) e laoshi, o honorável que ensina como um mestre do seu saber ${ }^{12}$. O mestre do Encontro de Saberes pode, assim, ser entendido como uma combinação parcial do amawta com o yachaj, do sensei com o shihan e do shifu com o laoshi. Dito ao contrário, "mestre" tanto poderia ser traduzido em quechua por amawta como por yachaj, o mesmo valendo para o japonês e o chinês. Em espanhol o termo maestro se restringe mais à figura do professor, e um termo possível seria o de sabedor - que não carrega com precisão as duas funções, de ensinar e de ser o grande conhecedor. Em inglês o termo master empregado por George Steiner não deixa de

\footnotetext{
${ }^{12}$ Agradecemos a Joaquim Monteiro pela ajuda na conceituação dos termos japoneses e chineses; e a Ladislao Landa pela definição dos dois termos quechua.
} 
carregar uma conotação de dominação e poder, bem distante da atitude acolhedora e amorosa dos nossos mestres e mestras.

Рara além da oposição entre o instrutor e o grande conhecedor, ocorre também, em outros países e nações, distinções entre as áreas do saber, cada uma delas reservando, em alguns lugares, termos diferentes para designar as diferentes áreas. Assim, na nação iorubá, por exemplo, o mestre onisegun é o mestre da cura, por ser o conhecedor das plantas medicinais e dos procedimentos de cura; e distinto do babalawo, o sacerdote de Ifá, que seria um mestre espiritual. Na nação Angola o termo equivalente, tanto de onisegun como de babalawo é o de nganga ${ }^{13}$. E também a tradição Igbo conta com o termo omalu, que pode representar os grandes conhecedores e ao mesmo tempo os sábios. ${ }^{14}$ E diferentes mestres das artes e dos ofícios são identificados com outros nomes distintos. Podemos resumir temporariamente as características gerais do termo mestre e concluir: ele unifica a docência, a pesquisa, a liderança e a sabedoria; e também a ciência, a tecnologia, a arte, a filosofia e a espiritualidade.

Partindo da gênese do projeto, mestre como instrutor das artes tradicionais foi talvez a рrimeira acepção do termo; logo foi estendido para os mestres das tecnologias, arquitetura, plantas medicinais, o que apontaria para a segunda acepção; em seguida lideranças políticas também foram incluídas, como caciques indígenas, líderes de comunidades agrárias; e com a chegada de mestres e mestras das tradições religiosas afro-brasileiras, a espiritualidade foi incorporada, dando mais concreção e espaço expressivo para nomear a presença da sabedoria no mundo acadêmico.

A justificativa formal do convite aos mestres para que venham ensinar nas universidades é inequivocamente epistêmica, a saber: eles sabem o que nós não sabemos e que por isso mesmo não podemos ensinar. Contudo, a motivação para trazê-los toca outras áreas da nossa psique acadêmica coletiva. Dissemos acima que a sabedoria não está mais presente no cotidiano do nosso mundo acadêmico. Entre a docência, a pesquisa, a liderança comunitária e a sabedoria, esta última parece sintetizar a maestria, como condição almejada e raramente realizada pelos docentes nas nossas universidades. Рara além do conteúdo das aulas ministradas, a dimensão da sabedoria é um fator de entusiasmo e mobilização que colabora para tornar possível a presença dos mestres nas universidades.

13 Para a discussão do conceito de nganga como mestre, ver Santos (2019) e Giroto (1999); para onisegun e babalawo, ver Giroto (1999).

${ }^{14}$ Sobre o omalu, ver Chimakonam (2015). 
O próprio termo mestre mobiliza a projeção do encontro com alguém que alcançou um estado de realização no que faz, e até mesmo transcendência em relação à sua base material (em geral precária) e social (muito frequentemente submetida a crises, discriminações, racismos, violência, etc). Essa conexão desejada, ainda que irrefletida, entre conhecimento e sabedoria, está presente em um plano simbólico e provavelmente subliminar nas bandeiras de muitas das nossas universidades, que contêm, inscrito em suas logomarcas, o termo sapientia. O significado deste termo, que remonta ao pensamento estoico e à antiguidade romana tardia, atravessou o surgimento das universidades ocidentais na Idade Média e chegou aos nossos dias, propondo fundir a noção de conhecimento (ou ciência) com sabedoria (ou dimensão espiritual, ainda que laica $)^{15}$. Mais ainda, uma revolução epistêmica provocada pelo Encontro de Saberes é justamente retomar a figura do mestre hoje, a qual guarda notáveis semelhanças com o lugar do mestre no mundo antigo (grego e romano), tal como teorizado brilhantemente por Pierre Hadot $^{16}$.

\section{A POLIMATIA E A TRANSDISCIPLINARIDADE}

A transdisciplinaridade vem adquirindo nas nossas universidades a forma crescente de um desejo, ou uma proposta de transformação, porém com poucos exemplos concretos de realização. Enquanto o discurso científico hegemônico coloca os saberes tradicionais, independente de sua localização e ancoragem étnica e racial, como o passado do mundo moderno, rebatemos esta tese afirmando que, na verdade, eles não foram superados, e simplesmente seguiram sua própria trajetória concomitantes com as transformações na ordem do saber acadêmico provocadas pela revolução científica ocidental e pelo capitalismo. Neste sentido, eles são, na verdade, um espelho do nosso futuro, porque nos trazem a realização transdisciplinar que ainda almejamos. E na medida em que os mestres são polímatos e praticantes de caminhos espirituais, eles realizam o componente da espiritualidade, ou da vida interior, descrito no Artigo 5 da Carta da Transdisciplinaridade: "A visão transdisciplinar é resolutamente aberta na medida que ultrapassa o campo das ciências exatas devido ao seu diálogo e sua reconciliação, não apenas com as ciências humanas, mas também com a arte, a literatura, a poesia e a experiência interior"17.

\footnotetext{
15 Para uma gênese da busca pela sabedoria face a aquisição de conhecimento e seus reflexos na academia atual, ver Brouwer (2014).

${ }^{16}$ Sobre o mestre antigo, ver Hadot (2014) e a excelente exposição da sua teoria por Davison (1995).

${ }^{17}$ Carta da Transdisciplinaridade (2008, p. 163).
} 
Conforme mencionamos acima, uma característica central dos mestres é a polimatia, o que contrasta, na maioria dos casos, com a especialização disciplinar dos professores parceiros. Apresentamos aqui cinco mandalas representando a polimatia alcançada por cinco mestres e mestras dos indígenas e duas afro-brasileiras. Trata-se, obviamente, de uma síntese dos seus saberes que ainda são mais vastos. Cada ponto da mandala se refere a uma área do saber acadêmico segundo as tabelas do CNPq, daí a tradução da polimatia dos mestres na nossa grade transdisciplinar.

Figura 2. Mandalas da transdisciplinaridade: Makota Kidoiale, Quilombo Manzo, BH, MG; Mestra na UFMG; Mapulu Kamayurá, Aldeia Kamayurá, Parque do Xingu, MT. Mestra na UnB; Ibã Huni Kuin, Aldeia Huni Kuin, AC; Mestre na UFMG; Mestre Maniwa Kamayurá, Parque do Xingu, MT. Mestre na UnB. Lucely Pio, Quilombo Cedro, GO, Mestra na UnB e UFMG.
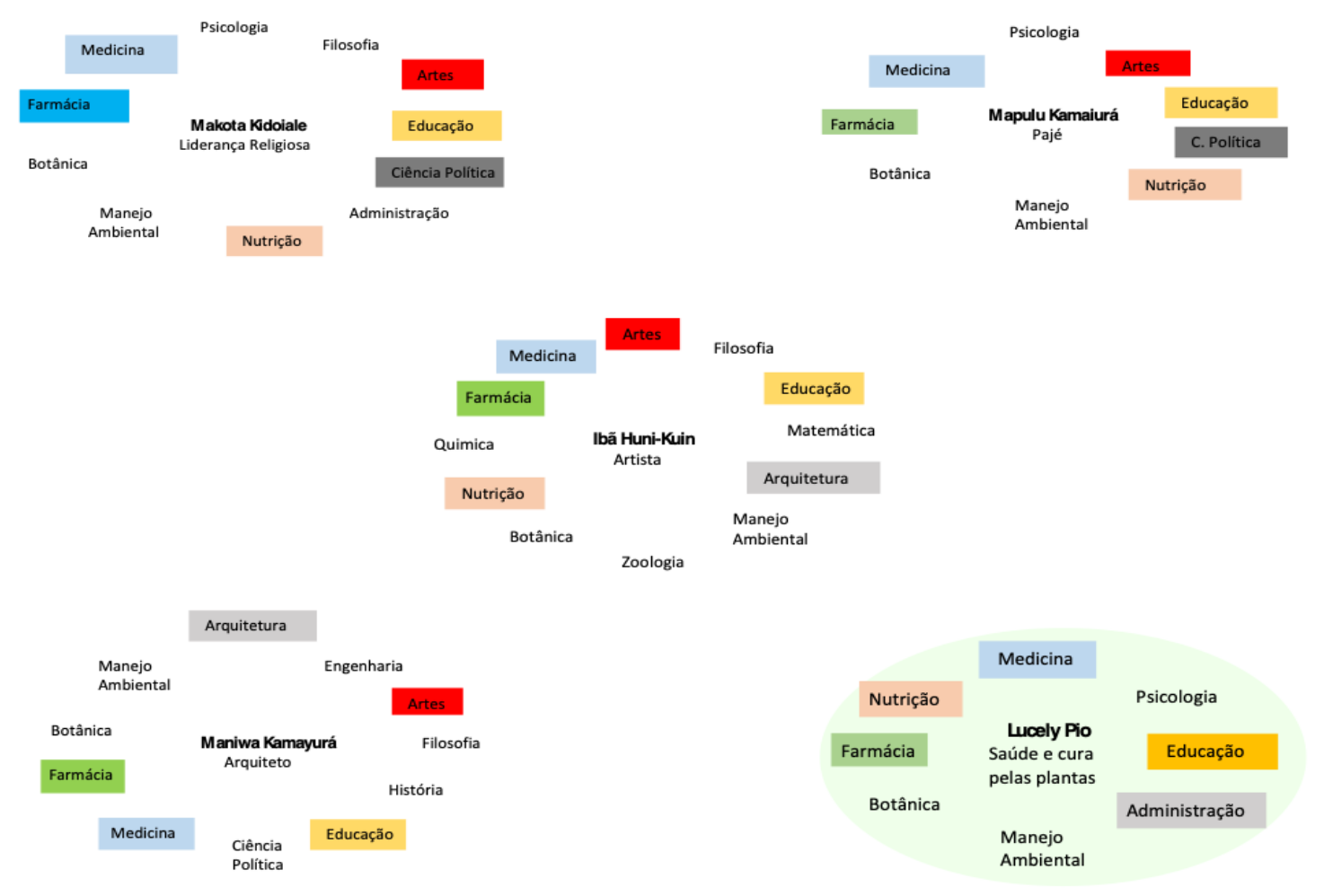

Fonte: INCTI/UnB/CNPq - 2020.

\section{O PROFESSOR PARCEIRO}

Ainda que não haja dúvida de que o mestre e a mestra sejam os sujeitos imprescindíveis para a existência do Encontro de Saberes, a disciplina não existiria sem a presença e a contribuição do professor parceiro. Alguns elementos básicos de sua atuação devem, portanto, 
ser apresentados. Em primeiro lugar, é preciso ter consciência de que uma aula da disciplina aberta com a metodologia do projeto deixa de ser uma relação diádica professor-aluno (que é o padrão de quase todas as aulas ministradas nas universidades) e se transmuta em uma relação triádica: mestre-aluno-professor parceiro. A meta do Encontro de Saberes é realizar o diálogo interepistêmico, e cabe ao professor parceiro o papel de promovê-lo devido à sua condição de anfitrião.

O professor parceiro cumpre o papel de anfitrião e de apoio para o mestre em sala de aula. Contudo, sua função não se esgota nessa tarefa pragmática e logística, por mais imprescindível que ela seja. Além de ensinar aos alunos um saber novo e muitas vezes único, o mestre (sempre um polímato) encarna a transdisciplinaridade tão buscada ultimamente na nossa universidade disciplinarizada, e seu encontro será um desafio para o professor parceiro, cuja formação é em geral disciplinar. Seguindo a ideia da relação triádica, teremos dois níveis de transmissão ocorrendo simultaneamente. A transmissão mais óbvia é a do mestre para os estudantes: lançando mão de sua pedagogia específica, o mestre transmite o seu saber, de acordo com a ementa que foi construída com a ajuda do professor parceiro. O segundo nível de transmissão ocorre, de um modo menos perceptível e formalizado, entre o professor parceiro e o mestre. Este foi convidado a ensinar um saber desconhecido na academia e ao fazê-lo exercita a polimatia, princípio de articulação do conhecimento que pode ser tomado como equivalente, na academia, da formação transdisciplinar. Como em um processo análogo a uma iniciação, o professor parceiro tem a chance rara de interagir com alguém que trilhou o caminho integrador do conhecimento a que damos o nome de transdisciplinaridade. Sintetizando, podemos dizer que, para os estudantes, o mestre realiza uma transmissão temática; para o professor parceiro ele oferece uma transmissão epistemológica.

Além dos papéis pedagógicos e epistêmicos, o professor parceiro é um mediador social em uma situação muito específica: construirá um vínculo com o mestre-docente diante da estrutura acadêmica, unificando tarefas que ele em geral desenvolve de um modo separado: as de ensino e de gestão, justamente as que se the apresentam como mais remotas entre si. Ou seja, ele media o mundo remoto do mestre como docente não somente no plano epistêmico, mas também nos planos operacional, didático e institucional.

Se contamos agora com um programa de ocupação de epistemes não-ocidentais nas universidades pelo Encontro de Saberes, devemos esclarecer mais uma vez que se trata de uma construção coletiva sem controle prévio, mais próxima da irrupção de um inconsciente acadêmico que interpelou a nossa rede de professores parceiros (e ao mesmo tempo foi por ela interpelado). Se tivemos essa esplêndida distribuição de várias tradições de saberes, sobre as 
quais comentamos logo acima; e se temos professores pertencentes a uma vasta gama das áreas científicas e humanas, esse processo se deu absolutamente sem um plano centralizador por parte do INCT de Inclusão, e muito menos por alguma instância de acordo prévio por parte dos professores parceiros de cada universidade da rede. O que chamamos aqui de inconsciente acadêmico é a soma das consciências e percepções dos professores (hoje parceiros) acerca da diversidade epistêmica brasileira e de sua baixa representação nos currículos com que operamos. Acreditamos que o Encontro de Saberes foi o catalisador de um processo de busca, mapeamento, contato e finalmente convite aos mestres e mestras dessa rica diversidade para que finalmente comecem a ocupar o espaço de docente ao nosso lado. Provavelmente, esse movimento que deveria ter sido iniciado há um século atrás, quando da instalação das primeiras universidades de corte ocidental moderno no Brasil.

O movimento cresceu devido à energia visionária dos professores parceiros, que em sua maioria já haviam estabelecido vínculos estáveis e de longa data com os mestres e mestras de diversas comunidades e povos tradicionais em que realizam pesquisas participativas e colaborativas. O INCT de Inclusão não induziu a abertura de disciplinas fora da UnB, apenas apoiou e estimulou solicitações específicas dos colegas que hoje compõem a nossa inspiradora Rede do Encontro de Saberes. Todos os indicadores dos resultados dos dez anos que apresentamos acima não foram produtos de metas estabelecidas a priori, mas resultado da mobilização do conjunto de professores parceiros. Em quase todas as universidades, as disciplinas têm refletido a variedade de saberes dos povos tradicionais de cada estado ou região que abriga os seus campi.

Рara concluir, estamos felizes em poder mostrar como em dez anos o movimento do Encontro de Saberes conseguiu colocar em marcha um movimento de refundação do sentido epistêmico das instituições superiores de ensino e pesquisa no Brasil. Até uma década atrás, os currículos das nossas universidades, praticamente em todas as áreas, das ciências às tecnologias, das humanidades às artes, reproduziam os currículos das universidades modernas ocidentais, oferecendo uma formação monoepistêmica e eurocêntrica e conduzida por docentes que adquiriram exclusivamente essa única formação. Todas as demais tradições de conhecimento, como as indígenas, quilombolas, de povos de terreiro, das culturas populares e dos demais povos tradicionais, ou estavam excluídas ou eram representadas apenas através da lente dos docentes de formação eurocêntrica. Assim entendido, o que tínhamos então era um mundo de conhecimento notavelmente reduzido e excludente, em uma combinação negativa de racismo étnico, fenotípico e epistêmico. O Encontro de Saberes oferece uma resposta positiva e factível ao modo colonizado e racista com que nossas universidades foram implementadas. Estamos 
ainda no início dessa refundação inclusiva e pluriepistêmica, e esperamos que o movimento se enraíze cada vez mais no nosso sistema acadêmico para que ele finalmente possa fazer justiça à abundância de saberes presentes nos nossos povos e comunidades tradicionais.

\section{REFERÊNCIAS}

II SEMINÁRIO NACIONAL DE POLÍTICAS PÚBLICAS PARA AS CULTURAS POPULARES. São Paulo: Instituto Pólis/Brasília: Ministério da Cultura, 2006.

BROUWER, René. The Stoic Sage. Cambridge: Cambridge University Press, 2014.

CARTA DA TRANSDISCIPLINARIDADE. In: NICOLESCU, Basarab. 0 Manifesto da Trandisciplinaridade. São Paulo: TRIOM, 1999. p. 161-165.

CARVAlHO, José Jorge. Metamorfoses das Tradições Performáticas Afro-Brasileiras: de Patrimônio Cultural a Indústria de Entretenimento. In: Celebrações e Saberes da Cultura Popular. Rio de Janeiro: Centro Nacional de Folclore e Cultura Popular/IPHAN, Série Encontros e Estudos, 2004. p. 65-83.

. Los Estudios Culturales en America Latina: Interculturalidad, Acciones Afirmativas y Encuentro de Saberes. Tabula Rasa, n. 12, p. 229-252, 2010a.

. "Espetacularização" e "Canibalização" das Culturas Populares na América Latina. Revista Anthropológicas, ano 14, v. 21, n. 1, p. 39-76, 2010 b.

. Universidades Empobrecidas de Conhecimento. Entrevista concedida por José Jorge de Carvalho à Revista de História da Biblioteca Nacional. Cadernos de Inclusão 3. Brasília. INCTI/UnB/CNPq, 2011. Disponível em: http://www.academia.edu/29536690/Universidades empobrecidas de conhecimento.pdf. Acesso em 21 em abril de 2021.

. Entrevista sobre o Encontro de Saberes com o professor José Jorge de Carvalho. Tempus - Actas de Saúde Coletiva, v. 6, n. 1, p. 17-22, 2012.

. Uma voz quilombola na contra-colonização da academia. In:BISPO, Antonio. Colonização, Quilombos. Modos e Significações. Brasília: Instituto de Inclusão no Ensino Superior e na Pesquisa, 2015. p. 9-15.

Transnational Interculturality in Music Education. An Original Contribution of Brazilian and Swedish Researchers. In: CORRÊA, Antenor Ferreira (Org.). Music in an Intercultural Perspective. Brasília: Strong Edições, 2016a. p. 11-12.

. Uma Proposta de Estudos Culturais na América Latina: Inclusão Étnica e Racial, Transdisciplinaridade e Encontro de Saberes. In: ALMEIDA, Júlia; PATROCínIO, Paulo Roberto Tonani do (Org.). Estudos Culturais: Legado e Apropriações. Campinas: Pontes Editores, 2017. p. 157-189. 
- Encontro de Saberes e Descolonização: Para uma refundação étnica, racial e epistêmica das universidades brasileiras. In: COSTA, Joaze Bernardino; TORRES, Nelson Maldonado; GROSSFOGUEL, Ramón (Org.). Decolonialidade e Pensamento Afrodiaspórico. Belo Horizonte: Autêntica, 2018. p. 79-106.

0 Encontro de Saberes nas Artes e as Epistemologias do Cosmos Vivo. In: TUGNY, Rosângela Pereira; GONÇALVES, Gustavo (Org). Universidade Popular e Encontro de Saberes. Brasília: INCT de Inclusão/ Salvador: EDUFBA, 2020b. p. 475-507.

Encuentro de Saberes y Descolonización. Una Refundación Étnica, Racial y Epistémica de las Universidades Latinoamericanas. In: ORTEGAS, Antonio; TOBAR, Javier (Org). Saberes Bioculturales. En Pie de Re-Existencias Bioculturales en el Sur Global, Granada: Editorial Universidad de Granada, 2020c. p. 107-129.

. Notório Saber para os Mestres e Mestras dos Povos e Comunidades Tradicionais: Uma Revolução no Mundo Acadêmico Brasileiro. $52^{\circ}$ Festival de Inverno da UFMG, Belo Horizonte. Ensaios Mundos Possíveis, Belo Horizonte: DAC/UFMG, 2020c. p. 1-18. Disponível em: https://issuu.com/culturaufmg

The Meeting of Knowledges in Music. The Inclusion of Masters of Traditional Musics as Lecturers in Higher Education Institutions. In: DIAMOND, Beverley; CASTELO-BRANCO, Salwa ElShawan. Transforming Ethnomusicology. Political, Social and Ecological Issues. Oxford: Oxford University Press, 2021. p. 185-206.

Transculturality and the Meeting of Knowledges. In: HEMETEK, Ursula; HINDLER, Daliah; HUBER, Harald; KAUFMANN, Therese; MALMBERG, Isolde; SAGLAM, Hande (Org.). Transkulturelle Erkundungen. Wissenschaftlich-künstleriche Perspektiven. Viena: Böhlau Verlag, 2019a. p. 79-94.

A Escola de Kyoto, a Filosofia Ocidental e as Artes Indígenas Amazônicas. Triálogo para a Construção de um Encontro de Saberes Filosóficos. In: NETO, Antonio Florentino; GIACOIA JR., Oswaldo (Org.). Ciência e Arte na Escola de Kyoto. Campinas: Editora PHI, 2019b. p. 105-126.

. Encontro de Saberes, Descolonização Transdisciplinaridade. Três Conferências Introdutórias. In: TUGNY, Rosângela Pereira de; GONÇALVES, Gustavo Gonçalves (Org.). Universidade Popular e Encontro de Saberes. Brasília: INCT de Inclusão/Salvador: EDUFBA, 2020a. p. 13-56.

. 0 Encontro de Saberes nas Artes e as Epistemologias do Cosmos Vivo. In: TUGNY, Rosângela Pereira de Tugny; GONÇALVES, Gustavo Gonçalves (Org.). Universidade Popular e Encontro de Saberes. Brasília: INCT de Inclusão/Salvador: EDUFBA, 2020b. p. 475-507.

- Notório Saber para os Mestres e Mestras dos Povos e Comunidades Tradicionais: Uma Revolução no Mundo Acadêmico Brasileiro. In: FESTIVAL DE INVERNO DA UFMG, 52, Belo Horizonte. Ensaios Mundos Possíveis. Belo Horizonte: DAC/UFMG, 2020c. p. 1-18. Disponível em: $<$ https://issuu.com/culturaufmg>. Acesso em 21 de abril de 2021.

. Encuentro de Saberes y Descolonización. Una Refundación Étnica, Racial y Epistémica de las Universidades Latinoamericanas. In: ORTEGAS, Antonio; TOBAR, Javier Tobar (Org.). 
Saberes Bioculturales. En Pie de Re-Existencias Bioculturales en el Sur Global. Granada: Editorial Universidad de Granada, 2020d. p. 107-129.

CARVALHO, José Jorge; FLÓREZ, Juliana. The Meeting of Knowledges: A project for the decolonization of universities in Latin America. Postcolonial Studies. Special Issue: Decoloniality, Knowledges and Aesthetics, v. 17, n. 2, p. 122-139, 2014.

- Encuentro de Saberes: Proyecto para decolonizar el conocimiento universitario eurocéntrico. Nómadas, v. 41, p. 131-147, 2014.

CARVALHO, José Jorge; ÁGUAS, Carla. Encontro de Saberes: Um Desafio Teórico, Político e Epistemológico. In: SANTOS, Boaventura de Sousa; CUNHA, Teresa (Org). Colóquio Internacional Epistemologias do Sul. Vol. 1: Democratizar a Democracia. Coimbra: Universidade Coimbra/Centro de Estudos Sociais, 2015. p. 1017-1027.

CARVALHO, José Jorge; FLÓREZ, Juliana Flórez; RAMOS, Máncel. El Encuentro de Saberes: Hacia una Universidad Pluriepistémica. In: AYALA, Nina Alejandra Cabra; RESTREPO, Camila Aschner (0rg). Saberes Nómadas: Derivas del Pensamiento Propio. Bogotá: Ediciones Universidad Central, 2017. p. 183-208.

CARVALHO, José Jorge; VIANA, Letícia Vianna; ÁGUAS, Carla. Encontro de saberes: política de inclusão de mestres das culturas tradicionais na docência do ensino superior. Anais do VI Seminário Internacional de Políticas Culturais. Rio de Janeiro: Fundação Casa de Rui Barbosa, p. 760-733, 2015. Disponível em: http://www.culturadigital.br/politicaculturalcasaderuibarbosa. Acesso em 21 de abril de 2021.

CARVALHO, José Jorge; VIANNA, Letícia; SALGADO, Flávia. Mapeando Mestres e Mestras dos Saberes Populares Tradicionais. Anais do VII Seminário Internacional de Políticas Culturais. Rio de Janeiro: Fundação Casa de Rui Barbosa, p. 1029-1038, 2016. Disponível em: http://rubi.casaruibarbosa.gov.br/xmlui/handle/20.500.11997/8769. Acesso em 21 de abril de 2021.

CARVALHO, José Jorge; KIDOIALE, Makota; COSTA, Samira Lima da; CARVALHO, Emílio Nolasco de. Sofrimento psíquico na universidade, psicossociologia e Encontro de saberes. Sociedade \& Estado, v. 35, $n$. 1, p. 135-152, 2020.

CARVALHO, José Jorge; COSTA, Samira Lima da. Processos de transmissão: 0 ensino universitário e 0 encontro com mestras e mestres dos saberes tradicionais. In: MONTEIRO, Ana Claudia Lima. Processos Psicológicos: Perspectivas Situadas. Niterói: EDUFF, 2020. p. 26-55.

CARVALHO, José Jorge; BARROS, Liliam; FERREIRA, Antenor; CHADA, Sônia. The Meeting of Knowledges as a Contribution to Ethnomusicology and Music Education. World of Music (New Series), v. 5, n. 1, p. 111$133,2016$.

CARVALHO, José Jorge; BARROS, Liliam; CORRÊA, Antenor Ferreira; CHADA, Sonia. 0 Encontro de Saberes como uma Contribuição à Etnomusicologia e à Educação Musical. In: LÜHNING, Ângela; TUGNY, Rosângela Tugny. Etnomusicologia no Brasil. Salvador: EDUFBA, 2016. p. 140-166. 
CARVALHO, José Jorge et al. Encontro de Saberes. Uma Experiência de Ensino e Aprendizagem no curso de Licenciatura em Música e no Programa de Pós-Graduação em Artes da Universidade Federal do Pará. Tucunduba, n. 5, p. 4-11, 2016.

CHIMAKOMAN, Jonathan (Org). Atuolu Omalu. Some Unanswered Questions in Contemporary African Philosophy. Lanham: University Press of America, 2015.

DAVISON, Arnold. Introduction: Pierre Hadot and the Spiritual Phenomenon of Ancient Philosophy. In: HADOT, Pierre. Philosophy as a Way of Life. Londres: Blackwell, 1995. p. 1-45.

FIGUEIREDO, Ana Flávia; VIANNA, Leticia C.R. 0 Encontro de Saberes e a Salvaguarda do Patrimônio Imaterial. Cadernos Naui: Núcleo de Dinâmicas Urbanas e Patrimônio Cultural, v. 9, n. 17, p. 90-104, 2020.

GIROTO, Ismael 0 Universo Mágico-Religioso Negro-Africano e Afro-Brasileiro: Bantu e Nagô. Tese de Doutorado de Antropologia - Universidade São Paulo, 1999.

HADOT, Pierre. A Filosofia como Maneira de Vier. In: HADOT, Pierre. Exercícios Espirituais e Filosofia Antiga. São Paulo: É Realizações, 2014. p. 261-274.

. 0 Sábio e o Mundo. In: HADOT, Pierre. Exercícios Espirituais e Filosofia Antiga. São Paulo: É Realizações, 2014. p. 311-326.

. The Figure of the Sage in Greek and Roman Antiquity. In: The Selected Writings of Pierre Hadot. Londres: Bloomsbury Academic, 2020. p. 185-206.

JUNG, C. G. Tipos Psicológicos. Petrópolis: Vozes, 2003.

LACAN, Jacques. A Ciência e a Verdade. In: LACAN, Jacques. Escritos. Rio de Janeiro: Zahar, 1998. p. 869892.

SANTOS, Tiganá Santana Neves. A Cosmologia Africana dos Bantu-Kongo por Bunseki Fu-Kiau: Tradução Negra, Reflexões e Diálogos a partir do Brasil. Tese de Doutorado em Estudos da Tradução - Universidade São Paulo, 2019.

SEMINÁRIO NACIONAL DE POLÍTICAS PÚBLICAS PARA AS CULTURAS POPULARES. São Paulo: Instituto Pólis/Brasília: Ministério da Cultura, 2005.

STEINER, George. Lições de Mestres. Rio de Janeiro: Editora Record, 2018.

VIANNA, Letícia Costa Rodrigues. 0 Projeto Encontro de Saberes:Educação Patrimonial e Inclusão Epistêmica. Revista Com Censo: Estudos Educacionais no Distrito Federal, v. 7, n. 3, p. 202-207, 2020.

Recebido em 21 de setembro de 2020. Aprovado em 01 de fevereiro de 2021. 